\title{
Адаптации Чехова в современной венгерской литературе
}

\author{
ILDIKÓ REGÉCZI \\ Debreceni Egyetem BTK Szlavisztikai Intézet, H-4032 Debrecen, Egyetem tér 1. \\ Institute of Slavic Studies, Faculty of Humanities, University of Debrecen \\ E-mail: iregeczi@yahoo.com
}

(Received: 6 December 2017; accepted: 7 February 2018)

\begin{abstract}
The creative reception of Anton Chekhov in contemporary Hungarian literature often takes the form of a role-play in which poets put on an authorial mask that displays Russian literary references, while their Chekhovian intertexts constitute an organic part of a playful evocation of classic Russian literature. The form of the mask lyric, including especially that of the so-called "oroszvers" (verbatim: a Russian poem), is also characteristic of poetry from across the border in Transylvania; more specifically, of the writers' generations starting out in the sixties and seventies, named after the book series entitled Forrás (Springs), growing up on the heritage of the 20th-century Hungarian poet Attila József, and apparently representing this heritage but, at the same time, introducing a new form of expression as well. This study focuses on the poetics of two such contemporary authors, László Király (b. 1943) and András Ferenc Kovács (b. 1959), in whose poetry I wish to examine the phenomenon belonging to the category of literary mystification, while analyzing the manifestations of the typical Chekhovian protagonist and the Chekhovian "atmosphere" as transposed into poetry.
\end{abstract}

Keywords: Chekhov, Hungarian literature, László Király, András Ferenc Kovács, literary mystification, mask lyric

Если и не в таком богатстве и изобилии, как в русской литературе, чеховские интертексты все же присутствуют и в современной венгерской литературе, в которой можно найти примеры самых разных ситуаций дописывания. Однако, что неожиданно, областью, наиболее восприимчивой к духовному наследию русского писателя и более всего стремящейся вступить с ним в диалог, является, в первую очередь, не проза или драма, а лирика. Помимо этого, возникает парадигматическая ситуация, в которой «творческое восприятие» Чехова часто осуществляется в форме мистификации, ролевой игры, в которой лирик скрывается за авторской маской, имеющей русские литературные коннотации, тогда как чеховский интертекст становится одним из средств вызова в памяти классической русской литературы или русского «Серебряного века» и игры с ними. Упомянутая авторская маска может также напомнить о другой, значительно более ранней ролевой игре в венгерской литературе. Повесть Гоголя «Шинель» первым перевел на венгерский язык великий классик XIX века Янош Арань (в 1860 г., с немецкого), после чего (через четыре года) он начал использовать имя Акакия Акакиевича в качестве литературного псевдонима. В рамках настоящей работы мы не можем подробно рассмотреть связь между использованием имени и текстами 
(статьями), принадлежащими данной маске, мы хотели бы только указать на мотив скрытности, на ироничное отношение к собственному имени, а также на исторический прецедент появления авторского персонажа, носящего черты какого-либо русского или псевдорусского героя.

Тем не менее, русский читатель может знать о явлении «русских стихов» в современном контексте со времени появления (2001 г.) венгерскорусского двуязычного издания ${ }^{1}$ сборника Иштвана Бака (1948-1995) «Завещание Степана Пехотного» (первое издание сборника, еще только на венгерском языке, но с русским переводом заглавий стихов, вышло в свет в 1994 г.). Послесловие на венгерском и русском языках к двуязычному изданию было написано Каталин Сёке, в котором она подробно анализирует «его русские стихи» и отмечает их поверхностное сходство с ролевыми стихами Андраша Ференца Ковача и Ласло Богдана (СЁКЕ 2001). В центре внимания настоящей статьи стоят лирические циклы Ласло Кирая и Андраша Ференца Ковача, имеющие отдаленную связь с поэтической игрой Иштвана Бака, но в то же время воссоздающие в рамках ролевых стихов образы одного или нескольких чеховских персонажей.

Мы можем говорить о парадигматической ситуации и прослеживаемых за псевдорусскими мистификациями закономерностях в еще одном отношении. Ролевые и, в том числе, «русские» стихи кажутся формой, свойственной также зарубежной, трансильванской венгерской лирике, а конкретнее - поколениям писателей, начинавших свое творчество в шестидесятые-семидесятые годы и получивших свое название от серии книг «Родник» (Forrás), которые выросли на поэтическом наследии Аттилы Йожефа и были явными представителями этого наследия, однако вместе с тем ввели в употребление и новый язык форм. К этим поколениям принадлежат Чаба Ласлофи, ${ }^{2}$ Ласло Кирай, Ласло Богдан и Андраш Ференц Ковач, в лирике которых часто появляется характеризованный русскими чертами образ - или в форме лирического героя, или как упоминание о фигуре русской литературы, или в самой маске автора. Изучение причин симптоматичного явления (т. е. почему основанная на создании масок поэтическая игра зародилась именно в этой особой географическо-исторической среде и почему именно эти поколения отдают ей свое предпочтение) не входит в нашу задачу. Темой интерпретации в настоящем случае являются сами временные параллели и нити, связывающие тексты Чехова с этими поэтическими мирами, перекликающимися также друг с другом.

В отношении творчества рассматриваемых здесь авторов - Ласло Кирая и Андраша Ференца Ковача - нужно отметить, что ролевые стихи и формирование масок могут быть интерпретированы как более устойчивая, охваты-

${ }^{1}$ Стихи сборника переведены Юрием Павловичем Гусевым. В научный дискурс тему обладающих русским культурным кодом стихотворений Иштвана Бака ввела Каталин Сёке (см. СЁКЕ 1997: 153-157).

${ }^{2}$ О связи творчества Чабы Ласлофи с русской культурой и о наблюдаемой в его поэзии ролевой игре, основанной на русской литературе, более подробно см. РЕгеци 2017. 
вающая не один текст лирическая речевая ситуация, за которой стоит значительная культурная открытость и готовность к культурному диалогу. Заслуживает внимания и тот факт, что Ласло Кирай - как и Иштван Бака - занимается художественными переводами с русского языка; его знание русской литературы и эрудиция ученого проявились и в его цикле статей по истории лирики «Буи» (Bóják), написанных для художественного журнала «Наш путь» (Utunk) (KIRÁLY 2008).

Ласло Кирай в сборнике стихов «Когда вы были маками» (Amikor pipacsok voltatok) создает образ «увиденного во сне поэта» А. Незванова (KIRÁLy 1982: 37-46). Поэтическая ролевая игра здесь не включает в себя детальную разработку фиктивной биографии, Кирай только размещает своего персонажа во времени. Согласно мистификации, автор, живший между 1900 - или, по версии сборника «Кладбище янычар» (Janicsártemetö), вышедшего на год позже и частично повторяющего стихотворения цикла (KIRÁLY 1983: 144), между 1903 - и 1938 годами, по звучанию своей фамилии имеет русское происхождение, но на самом деле является «безымянным» (на что намекает и его фамилия); его стихи в дальнейшем, по сути, входят во все издаваемые лирические сборники. В лирических текстах цикла, адресатом части которых является некая Таня Смирнова, получает важную роль дуэт памяти и забвения. Эта дихотомия также является центральным мотивом в одном из стихотворений «Легенды о Незванове», входящем в сборник «Загнание» (Beüzetés) и вызывающем в памяти поэтику Чехова (KIRÁLY 1995: 45-47).

Заглавие входящего в сборник стихотворения «Дом воспоминаний. Чехов» (Emlékek háza. Csehov) имеет двойную кодировку. С одной стороны, в заглавии намечается предмет воспоминаний, что делает однозначными образ и тексты вовлеченной в стихотворение культурной памяти. Первая часть заглавия повторяется в паратексте стихотворения «Дом воспоминаний. Херваи» (Emlékek háza. Hervay), напоминающего о поэтессе трансильванского происхождения, Гизелле Херваи и включенного в сборник «Ночные дожди» (Ejféli esők). В этом же сборнике публикуется второй раз и стихотворение о Чехове. Параллельные названия намекают на акт воспоминания, используя мотив дома в значениях содержания жизни, собрания или галереи творческих достижений. С другой стороны, сам «дом воспоминаний» также является многократно тематизированным элементом и у Чехова. В лирической речи, хранящей главным образом следы драматических текстов русского классика, образ «покинутого, запущенного», «пустого дома» выдвигает на первый план совокупность идей покидания дома (родительского дома, городского жилья, сельской усадьбы), его запустения, с одной стороны, и отправления в путь, открытости перед новыми переживаниями, с другой стороны, т. е. амбивалентный опыт забвения и памяти.

Наряду с мотивом пустого или приходящего в запустение дома, служащего метафорой памяти, не менее важным является мотив двойственности и смены живого и безжизненного начал. Дом, по которому «бродит» воспоминание о ком-либо, оживает и сам («Пустой дом гулким голосом говорит: / 
мы - люди» [,Az üres ház azt mondja kongó hangon: / emberek vagyunk”]). Его делают живым следы чувств, память о субъективных переживаниях человека, беззащитного перед безграничностью судьбы. После всего этого - так же, как и у Чехова - неожиданно звучат патетические речи, игнорирующие течение времени, утверждающие жизнь и действие, за которыми, однако, следует ироническая саморефлексия. Вторая часть поэтической речи воссоздает элементы декораций пьесы «Чайка» («садовый прудик», «сцену без занавеса») и обращается к одному из центральных персонажей пьесы, Нине, с освобождающим, раскрепощающим обещанием отъезда, осуществляющим ее мечты о счастливой жизни. Тем не менее, вопросы, заданные в конце стихотворения, опять вселяют неуверенность, лирическое «я» переспрашивает, возможно ли счастье, и реально ли сделать осмысленным приключение Человека. Строки, следующие за повторяющимся словом «приключение», подчеркнутом также типографически (набор одними заглавными буквами) и выражающем концентрированные эмоции посредством совместного использования вопросительного и восклицательного знаков, обозначают часть, которая может читаться как своего рода эпилог. Изменение реферированного текста также отражает дополнительный, завершающий характер последних двух строф. В то время как завершающий мотив (персонаж, собирающийся в путь) перекликается с финальными концовками, знакомыми из чеховской поэтики, поэтика имен разветвляет память, в процесс переписывания воспоминаний вовлекаются также прозаические тексты Достоевского (Порфирий, Настасья) и Толстого (Анна Михайловна). Конструируется интертекстуально многослойный текст, провоцирующий читателя путем повторного задания хранящихся в культурной памяти вопросов, играющий напряженной амбивалентностью.

В то время как у Ласло Кирая читателя ориентирует в направлении Чехова лишь случайная, единичная интертекстуальная связь, у Андраша Ференца Ковача мы можем говорить о последовательно построенном цикле, чей паратекст однозначно указывает на активное участие чеховского следа в процессе построения значений. Сборник Андраша Ференца Ковача «Наследие Алексея Павловича Астрова» (Alekszej Pavlovics Asztrov hagyatéka, 2010) в определенном смысле является продолжением сборника «Ангелы в адвентском морозе» (Adventi fagyban angyalok, 1998), в котором впервые размещены «стихи Алексея Астрова», входящие также в данную коллекцию, и которая - в виде примечания - впервые приводит краткую фиктивную биографию Алексея Астрова. Согласно ей, Астров родился в конце XIX века в Санкт-Петербурге, был врачом и поэтом, и «принадлежал к великому (утонувшему и утопленному) поколению русской лирики XX века» (KovÁcs 2010: 121). Близкий друг Булгакова (его стихи, согласно поэтической игре, были изданы профессором Андреем Преображенским) в своей непростой жизни преуспел во множестве профессий и ролей, которые в то же время могут считаться знаками переломных моментов российской истории XX века, транспонированными в историю личной жизни. Год смерти Астрова - 1985, место смерти - Москва. 
«Забытый всеми» Алексей Астров (KovÁcs 2010: 120), исходя из его фамилии, является изначально чеховским созданием («Дядя Ваня»), а его имя и (появившееся как новый элемент по сравнению с прежним сборником) отчество указывают на самого автора - Чехова (Алексей ${ }^{3}$ Павлович - Антон Павлович). В то же время, созданный образ Астрова также реагирует и на ролевую игру Иштвана Бака, что явствует из эпиграфа к циклу, взятого из «Завещания Степана Пехотного», из посвящения стихотворения «Отрывок Алексея Астрова» (Alekszej Asztrov töredéke) (In memoriam B. I.), и из заглавия стихотворения «Памяти Степана Пехотного» (Sztyepan Pehotnij emlékére). Но в стихах скрываются и другие бесспорные «следы»: первичный адресат стихотворения «Письмо моим друзьям» (Levél barátaimhoz) - Пехотный, тогда как вторым другом является созданный Ласло Кираем Незванов. Кроме того, адресатом «дружеского рондо» в сборнике становится и Богданов, бывший одной из поэтических масок Ласло Богдана, неоднократно реагировавшего в своем творчестве на поэтику Андраша Ференца Ковача. ${ }^{4}$ А намек, скрытый в заглавии сборника (Андраш Ференц Ковач называет свою коллекцию стихов наследием, тогда как Бака - завещанием) также обрисовывает тот своеобразный временной аспект, из которого звучит лирическое «я» стихов - как бы по другую сторону жизни или, по крайней мере, в ракурсе видения жизни из некоего удаляющегося, размытого существования. Кроме того, помимо акта вспоминания, Иштван Бака также незримо присутствует на заднем фоне лирической речи как посредник, переводчик лирики «Серебряного века», составляющей культурный контекст стихов, а кое-где - даже их непосредственный предмет.

Появление Алексея Павловича Астрова в качестве автора переосмысливает и расширяет реальную авторскую роль. Имя поэта на обложке книги заключено в скобки, таким образом, скрывающийся субъект уступает свое место Алексею Павловичу Астрову. Автор раскрывает перед нами созданную им биографию, пронизывающую весь паратекст (см. также образ на обложке), дополняя ее новыми подробностями и еще более детально разрабатывая ее в послесловии к данной книге, сохраняя, однако, элементы предполагаемости («может быть»), неопределенности и неясности. Он приводит подробности об открытии и медленном принятии Астрова (сдабривая свои определения жесткой оценкой литературной критики), затем - указывая на санкт-петербургского литературного критика Яковлева в качестве источника новых биографических данных - автор более подробно описывает семейную

${ }^{3}$ Согласно одному предположению относительно имени Алексей, за ним непосредственно скрыт персонаж Достоевского - Алеша Карамазов («Братья Карамазовы») (HoRVÁTH 2017: 135). Однако можно обоснованно предположить и другой источник. Вдохновителем мог быть и Булгаков, в другом месте также сыгравший роль в присвоении имен персонажам (см. замечание выше): персонаж его пьесы «Дни Турбиных»- Алексей Турбин.

${ }^{4}$ Создание Василия Богданова, второго «я» Ласло Богдана, происходит поэтическим методом, напоминающим фикционирование образа Астрова у Андраша Ференца Ковача, ср. «Рикардо Рейс в Сибири» (Ricardo Reis Szibériában, 2015), «Иллюзионист и чудовище» (Az illuzionista és a szörnyeteg, 2015). 
обстановку писателя, его странствия, прозаические труды, обвинение, арест и важнейшие моменты его дальнейшего «абсурдного хождения по мукам» (KovÁcs 2010: 111). «Примечание» к предыдущей книге, а также объемное послесловие к сборнику стихов «Наследие Алексея Павловича Астрова» (Alekszej Pavlovics Asztrov hagyatéka) обнаруживают научный подход, отличающийся от исходной лирической ситуации. Целью литературоведческой маски и установки, подражающей точности филологических работ, является отдаление текстов от персоны автора, который, как кажется, обретает свой «исповедный», индивидуальный голос только в самом конце сборника, дополнив послесловие более личной концовкой: «Признание об Алексее Павловиче Астрове» (,Vallomás Alekszej Pavlovics Asztrovról”).

Общей особенностью эпиграфов к этому признанию (строк из Блока, Чехова [от Астрова из «Дяди Вани»], Пушкина) является то, что все они говорят о старости как о состоянии бытия, но в особом ракурсе - ракурсе творчества («Завет служенья Непостижной»; «красота»; «романа»), дающего смысл грустной, потускневшей жизни (Блок: «глух», «черты до ужаса недвижны», Чехов: «испошлился, притупились все чувства»), уже не знающему пылких чувств существованию (Пушкин: «Блажен, кто праздник Жизни рано / Оставил, не допив до дна»). Тем не менее, признание и само усиливает исходную ситуацию посредничества: «Алексей Павлович... опять может диктовать самого себя мне, через меня, потому что я, нереальный и неактуальный венгерский поэт и так допишу, дополню его канувшее в забвение в России поэтическое искусство...». ${ }^{5}$ Как показывает эта цитата, роль посредника также включает в себя и дополнение, незаписанное, но выдержанное в духе Астрова и Чехова продолжение. Несмотря на то, что, согласно фикции, мы изучаем документы жизни автора, рассматриваем предметы его «памятной серии» (KovÁCs 2010: 104), бессмертие текстов все же направляет нас и побуждает к дополнению.

Эпиграфы к послесловию дают дальнейший ключ к интерпретации образа, произведенного в автора. Цитата из Осипа Мандельштама иллюстрирует отношение вещи и обозначающего его слова метафорой тела и души: «И вокруг вещи слово блуждает свободно, как душа вокруг брошенного, но не забытого тела» (KovÁcs 2010: 99). Таким образом, и имя Астрова является лишь условным знаком источника стихов, дающим форму интеллектуальнодуховному содержанию, жаждущему лирического выражения. В то же время, также цитируемые в качестве эпиграфа строки Чехова ${ }^{6}$ (пропитывающие

5 „Alekszej Pavlovics... ismét nekem, rajtam keresztül diktálhatja megint önmagát, mert én, a való- és korszerütlen magyar poéta, majd úgyis továbbírom, kiegészítem az ő oroszhoni feledésbe hullt költői életmüvét..." (KovÁCs 2010: 126).

${ }_{6}^{6}$ «е, которые будут жить через сто, двести лет после нас и которые будут презирать нас за то, что мы прожили свои жизни так глупо и так безвкусно, - те, быть может, найдут средство, как быть счастливыми, а мы... У нас с тобою только одна надежда есть. Надежда, что когда мы будем почивать в своих гробах, то нас посетят видения, быть может, даже приятные» (KovÁcs 2010: 99). 
данное творчество наподобие подземного источника) протягиваются между бессмысленностью настоящей жизни и прекрасным видением будущего, вследствие чего получает акцент позиция ретроспекции, мотив, вызывающий в памяти автора XIX века. Схожим образом, в третьем эпиграфе, в цитате из Пруста, также идет речь о забвении и о реальности литературы, понимаемой как пространство памяти, опять же конфронтируя читателя с созданием лирического текста, фиксирующего следы и воспоминания: «Книга - это большое кладбище, где на многих плитах нельзя уже прочесть стертые имена» ${ }^{7}$ (KovÁcs 2010: 99, 119). Особо интересно в эпиграфах, что в послесловии они указаны как часть наследия Астрова, цитаты, записанные поэтом на листках бумаги, которые попали в разные книги по случайности. Эта поэтическая игра намекает на многослойную интертекстуальную связь, опять же вызывающую в воображении образ кладбища или, скорее, бродящего между его могилами воспринимателя, пытающегося прочитать их надписи.

Наложение друг на друга визуальных элементов и вербального измерения показано и такими названиями циклов как «Колхидская фотография» (Kolkhiszi fénykép), «Закатный свет в металлической рамке» (Alkonyfény fémkeretben). Воспоминание, продолжающее жить в форме изображения, в первой главе сборника привязано к конкретной географической местности, Колхиде, играющему в белом и синем цветах Причерноморью, чье метафизическое значение снова усиливается эпиграфами, отрывками из Мандельштама, Есенина и, опять же, Пехотного. Русские ландшафты и русский дух воссоздаются в цикле также и посредством названий множества русских городов (Новгород, Москва, Баргузин, Красноярск, Иркутск, Владимир, Пермь, Владивосток, Витебск, Тобольск, Томск, Воронеж, Сталинград и т. д.), охватывающих чуть ли не всю российскую географию, все основные географические регионы России), рек (Волга), гор (Урал), реалий (пирог, чай, «Правда», водка, дача), деятелей искусства (кроме Чехова, например, Пушкин, Лермонтов, Достоевский, Булгаков, Рублев) и литературных персонажей (Алексей, Соленый, Елена Аркадина [некий комплексный образ Аркадиной из «Чайки» и Елены из «Дяди Вани»]).

Центральными темами сборника являются российская реальность, русский «Серебряный век» и трагические судьбы русских писателей в последовавшем за ним XX веке: приобретающий всеобъемлющее значение, расширенный до масштабов всеобщего опыта бытия конфликт между властью и художником. Противостояние лирического «я», «мокрого пса» и «стаи» ${ }^{8}$ является такой темой, «которая может случиться со всяким... Сегодня... Завтра».

${ }^{7}$ Ощущению культурного простора содействуют и многократно встречающиеся в книге чужие фонетические элементы. Французский эпиграф из Пруста (позже приведенный также в венгерском переводе), некоторые комбинации слов, рассматриваемые ниже географические названия, наименования культурных учреждений и акустическая структура российских реалий - все они служат воссозданию чужой культуры.

${ }^{8}$ Метафорические образы стихотворений «Письмо моим друзьям» (Levél barátaimhoz), «Собачья серенада» (Kutyaszerenád) и «Эпилог для Булгакова» (Epilógus Bulgakovnak). 
«У меня то, что иногда меня нет...» ${ }^{9}$ - читаем в продолжении строки. Основной позицией лирического «я» является основанное на слиянии прошлого и настоящего, исчезающее и размывающееся в нечто другое бытие, которое появляется в сборнике многообразно варьируясь и трансформируясь.

В то же время, размывание грани между живыми и мертвыми также дополняется идеей проходимости реальных и фиктивных позиций автора и его создания. Астров, как бывший чеховский персонаж, в стихотворении «Соленый прощается» (Szoljonij búcsúzik), чьим автором, согласно мистификации, он является, передает слова другого героя Чехова, штабс-капитана, известного по пьесе «Три сестры». В стихотворении транспонированный в романтического героя персонаж пьесы, литературный образ, выступающий против лживого, мелочного, механического, бессмысленного существования и желающий прожить - по лермонтовскому примеру - как можно более полную жизнь, обращается к своему автору, одновременно указывая также на смерть последнего («Бокал шампанского и за меня / Выпейте как-то, доктор...») (см. KovÁcs 2010: 16).

Персонажи русской культуры, а точнее, авторы начала XX века и нескольких последующих десятилетий в самом деле появляются в цикле «Закатный свет в металлической рамке» (Alkonyfény fémkeretben) как представители «исчезнувшего поколения» (KovÁcs 2010: 31). Образ Астрова и его голос принадлежат современнику из этого «поколения девяностых». В стихотворении «Московские панорамы» (Moszkvai panorámák) мы видим его тень на Тверской, а в сонете «Экспромт для одного актера» (Impromptu egy színészhez) поэт Астров приветствует актера Иосифа Биронского, то есть современного трансильванского актера Йожефа Биро.

По сути, картины грозного прошлого (и будущего) сопровождают акты воспоминания во всем цикле «Pulvis et umbra». Большинство стихов воздвигает памятник писателям начала XX века, что становится явным из паратекста стихов: мы читаем посвящения Бродскому, Цветаевой, Блоку, Есенину, Гумилеву, Арсению Тарковскому и Мандельштаму, либо же на этих авторов указывает подзаголовок. Выделим из стихотворений цикла те, которые указывают на Чехова: «Чехов на Капри» (Csehov Capriban), «Доктор Астров возвращается домой» (Asztrov doktor hazatér). И, несмотря на то, что автор посвящает стихотворение «Этюды к героическому эпосу» (Etüdök höseposzhoz) Борису Пастернаку, его заглавие также отсылает венгерского читателя к сочинениям Чехова, поскольку чеховская адаптация Никиты Михалкова «Неоконченная пьеса для механического пианино» известна венгерской публике под названием «Этюды для механического пианино» (Etüdök gépzongorára). Основными темами стихов являются моменты, связанные - возможно, несколько насильно - с биографией Чехова (констатация врачом-писателем собственной приближающейся смерти и заявление о «факте» несбывшегося

9 „[M]i bárkivel megeshetik... Ma... Holnap”. „Én úgy vagyok, hogy néha nem vagyok...” (KovÁCs 2010: 10). 
путешествия), а также боль и страдания, причиненные историческим водоворотом судеб. В то же время, чеховско-астровская судьба появляется в цикле также как более личное переживание, показанное смывающимися воедино образами живущего в микрорайоне и ездящего в библиотеку на велосипеде поэта семидесятых-восьмидесятых годов и доктора Астрова. ${ }^{10}$ Несмотря на то, что значительная часть стихотворений формально предстает перед нами как чеховский палимпсест, в формах лирической речи можно узнать поэтику «Серебряного века», а также Пушкина и Лермонтова. Более того, ссылки на иконические фигуры русской культуры и на русские традиции неоднократно переплетаются с имеющей ассоциативную силу литературной традицией венгерской культурной среды. ${ }^{11}$

Андраш Ференц Ковач выстраивает своего рода пантеон поэтического языка конца XIX и начала XX века, стремясь охватить его полностью. В процессе он вписывает и себя в эту культурную традицию, разыгрывая то, что он является участником, более того, продолжателем начатого, но считающегося неоконченным творчества реальных или фиктивных авторов. В его стихах первичным является не голос чеховских творений, и не всегда мир чеховских текстов, а скорее вырастающий из них и понимаемый как их органичное продолжение голос литературы «Серебряного века». Все три цикла пронизывает ощущение отсутствия этого голоса и этих авторов, плетущая трагические писательские судьбы реальность исторических обстоятельств.

Как видно из попытки интерпретации перечисленных выше произведений, тексты Чехова несут в себе такой культурный потенциал, который способен зазвучать по-новому даже в чужом, во многом отличающемся от исходного культурном контексте. Кроме того, парафразы Ласло Кирая и Андраша Ференца Ковача - будучи, в основном, интертекстами, связанными с формированием позиции собственного «я» - являются бесспорными доказательствами того, что здесь речь идет об обновлении традиции, которая уже ведет себя не как запас, а обращается к нам как форма опыта самоинтерпретации. ${ }^{12}$ Общей особенностью переписывания чеховских текстов венгерскими

${ }^{10}$ Тем не менее, согласно данному в послесловии объяснению, речь идет об одном и том же персонаже: о рожденном в конце прошлого века Астрове, который, в последнем десятилетии своей невероятно долгой и невероятно богатой поворотами судьбы жизни, дополняет свою пенсию, подрабатывая в качестве помощника библиотекаря (cp. KovÁCs 2010: 113-114).

${ }^{11}$ Например, в стихотворении «Романс, русский романс» (Románc, orosz románc) повторяющаяся наподобие припева строка («Глаза свои смежил и Пушкин»- „Szemét lehunyta Puskin is") вызывает в памяти стихотворение Аттилы Йожефа, начинающееся со строки «Смежает небо синий взор...» («Колыбельная» - Altató, перевод В. Ильиной) (ЙожЕФ 1958: 181). Можно также наблюдать подобное культурное «совместное воздействие» в любовном стихотворении «Песнь о каштановом дереве. Даше с любовью» (Dal a gesztenyefáról. Dásának szerelemmel), которое даже своим паратекстом отсылает к стихотворению Януса Паннониуса «О задунайском миндальном дереве» (Egy dunántúli mandulafáról).

${ }^{12}$ В данном случае считаем возможным расширенное применение выводов Эрнё Кульчара Сабо относительно поэтической практики Андраша Ференца Ковача (KULCSÁR SzABÓ 1994: 184-185). 
авторами является то, что технические новшества постмодернизма, главным образом, явление интертекстуальности, понимаемой как реализуемое в бесчисленном количестве форм отношение заимствования, активирует дополнительные слои мышления, которые читатель «причитывает» к данному лирическому тексту. Благодаря этому, новые формы поэтической речи, основанные на раздвоении лирического «я» (я и моя роль), и поэтика, основанная на кажущихся непривычными для лирики приемах, также делают явным побуждающее к продуктивности богатство русского классика XIX века.

\section{Литература}

Horváth 2017 = Horváth Kornélia: Kovács András Ferenc Adventi fagyban angyalok címü kötetének néhány orosz vonatkozásáról. In: GYÖNGYÖSI Mária (szerk.): Ad vitam aeternam. Tanulmánykötet Nagy István 70. születésnapjára. Budapest: ELTE BTK Orosz Nyelvi és Irodalmi Tanszék, 2017. 131-137.

KIRÁLY 1982 = KIRÁLY László: Amikor pipacsok voltatok. Bukarest: Kriterion, 1982.

KIRÁLY 1983 = KIRÁLy László: Janicsártemetö. Budapest: Magvető, 1983.

KIRÁLY 1995 = KIRÁLY László: Beüzetés. Marosvásárhely: Mentor, 1995.

KIRÁLY 2008 = KIRÁLY László: Bóják. Kalandozás a modern költészet tájain. Kolozsvár: Erdélyi Híradó, 2008.

KovÁcs 2010 = KovÁcs András Ferenc: Alekszej Pavlovics Asztrov hagyatéka. Csíkszereda: Bookart, 2010.

KulcsÁr Szabó 1994 = Kulcsár Szabó Ernő: Poesis memoriae. A lírai mnemotechnika és a kulturális emlékezet „újraírása” Kovács András Ferenc verseiben. In: KulcsÁR SzABó Ernő: Az új kritika dilemmái. Az irodalomértés helyzete az ezredvégen. Budapest: Balassi, 1994. 164-195.

ЙожЕФ 1958 = ЙожЕФ Аттила: Стихотворения. Переводы с венгерского. Москва: «Государственное издательство художественной литературы», 1958.

РЕГЕци 2017 = РЕГЕци Ильдико: Поэзия Чабы Ласлофи в диалоге с русской литературой. Slavica 46. Debrecen, 2017. 85-93.

СЁКЕ 1997 = СёКЕ Каталин: Стихотворения Степана Пехотного. Смена масок переводчика и поэта. Slavica 28. Debrecen, 1997. 153-162.

СЁКЕ 2001 = СёКЕ Каталин: Иштван Бака и его «русские стихи». «Завещание Степана Пехотного». In: BAKA István: Sztyepan Pehotnij testamentuma / Завещание Степана Пехотного. Szeged: Tiszatáj Alapítvány, 2001. 98-114. 